\title{
La autogestión educativa y la gubernamentalidad liberal como \\ superficie de emergencia de la educación popular*
}

Revista Colombiana de Educación, N. ${ }^{\circ} 65$. Segundo semestre de 2013 Bogotá, Colombia.
//Educational self-management

and liberal governmentality as an

emergency area of popular education

//A autogestão educacional e a

governamentalidade liberal como superficie de emergência da educação popular

Alejandro Álvarez Gallego**
Recibido: 29/07/2013 Evaluado: 29/08/2013
$*$
Este artículo es uno de los resultados investigativos del subproyecto "Educación Popular. Trayectos políticos y con- fluencias teóricas. Colombia 1970-2008", realizado con Claudia Rocío Carrillo como coinvestigadora; hizo parte de proyecto interuniversitario "Paradigmas y conceptos de la educación en Colombia", aprobado por Colciencias con el código 1115-452-21145 bajo la coordinación de Jesús Alberto Echeverri, profesor de la Universidad de Antioquia. Trabajo realizado en el periodo 2009-2010.
Profesor Universidad Pedagógica Nacional, investigador Grupo Historia de la Práctica Pedagógica. Correo electrónico: rizoma.alejandro@gmail.com

\section{Resumen}

El artículo pretende desarrollar una tesis que ha sido trabajada en el proyecto de investigación: "Educación popular. Trayectos políticos y confluencias teóricas. Colombia 1970-2008" que a su vez hizo parte del macro proyecto "Paradigmas y conceptos de la educación en Colombia". Para ello se esboza en primer lugar el problema: la educación popular, más allá de la vigencia o la pertinencia de sus postulados, hizo parte de un cambio histórico en el modo de gobernarnos que nos está llevando a la autogestión educativa. En seguida se identifica como superficie de emergencia de la llamada gubernamentalidad liberal, cuatro dinámicas distintas: 1. la irrupción de un mundo nuevo, 2. los discursos oficiales, 3. Ios discursos alternadivos, 4. el discurso religioso. Como resultado de estos movimientos se legitimó la idea de la autogestión educativa y así se describe en lo que llamamos los efectos pos-revolucionarios, que se materializan en el movimiento de los derechos humanos y la perspectiva culturalista, y en el Ilamado capitalismo cognitivo. La conclusión que se deriva de este trabajo es que la escuela y la educación formal están siendo hoy presionadas para que se flexibilicen sus estructuras y se amplíen sus fronteras tradicionales, generando una desadaptación que afecta a los jóvenes, a los maestros y a los protagonistas tradicionales de la institución educativa. Con ello queremos problematizar nuestro presente y dejar abiertas preguntas sobre la procedencia de las verdades pedagógicas que hoy parecen tan obvias.

\section{Abstract}

This article seeks to develop a thesis which has been worked on in the research project: "Popular education. Confluences theoretical and political trips" which in turn formed part of the macro-project 'Paradigms and concepts of education in Colombia.' It thus firstly outlines the problem: popular education, beyond questions of validity or the appropriateness of its proponents, was part of a historical change in the way in which we are governed which is bringing us to educational self-management. Following this, the article identifies four distinct dynamics of the emergency area of socalled liberal governmentality: 1. The development of a new world, 2. Official discourses, 3. Alternative discourses, 4. Religious discourse. As a result of these movements, the idea of

\section{Palabras Clave}

Educación popular, gubernamentalidad liberal, autogestión.

\section{Keywords}

Popular education, liberal governmentality, self-management.

\section{Palavras chave}

Educação popular, governamentalidade liberal, autogestão. 
self-management has become legitimate and it is here described as part of what we call post-revolutionary effects, which materialize in the human rights movement and the culturalist perspective and in the so-called cognitive capitalism. The conclusion reached in this article is that school and formal education are today subject to pressure to make their structures more flexible and to broaden their traditional boundaries, creating a maladjustment which affects young people, teachers and traditional protagonists within educational institutions. To this end, we seek to problematize our present and leave open questions about the origin of pedagogical truths, which today seem so obvious.

\section{Resumo}

O artigo se propõe desenvolver uma tese trabalhada no projeto de pesquisa "Educação popular. Trajetórias políticas e confluências teóricas" que fez parte do macro projeto "Paradigmas e conceitos da educação na Colômbia". Em primeiro lugar, se mostra o problema: a educação popular, além da vigência ou permanência das suas postulações, fez parte de uma mudança histórica no modo de governarmos, modo que nos está levando para a autogestão educativa. Seguidamente se identificam quatro elementos que agiram como superfície de emergência da chamada governamentalidade liberal: 1) a irrupção de um mundo novo; 2) os discursos oficiais; 3) os discursos alternativos; 4) o discurso religioso. O resultado desses quatro elementos foi a legitimação da ideia da autogestão educativa que é descrita no que se chama os efeitos pós-revolucionários, materializados no movimento pelos direitos humanos, a perspectiva culturalista e o chamado capitalismo cognitivo. A conclusão derivada deste trabalho é que a escola e a educação formal estão sendo hoje pressionadas para flexibilizarem as suas estruturas e ampliarem as suas fronteiras tradicionais, gerando uma desadaptação que afeta os jovens, os professores e os protagonistas tradicionais da instituição educativa. Assim, se busca problematizar o nosso presente e deixar perguntas abertas sobre a proveniência das verdades pedagógicas que hoje se apresentam como obvias.

\section{Planteamiento del problema}

La educación popular (EP) ha sido considerada por muchos de sus impulsores como una de las expresiones más poderosas del pensamiento emancipatorio que ha tenido América Latina. Aunque muchos de los postulados que la inspiraron ya no tienen la misma vigencia, sigue convocando a los movimientos de resistencia política que hoy luchan, desde horizontes distintos, contra el sistema capitalista y contra todas las formas de dominación. Sin embargo, cada vez es más difícil enmarcarla en las tesis que la originaron y muchos autores convienen en relacionarla con los nuevos movimientos sociales que reivindican la diversidad cultural y la defensa de los derechos de las poblaciones que se consideran discriminadas por su opción sexual o religiosa, o por su condición de género, edad o clase. En sus años de emergencia (1960-1970), se discutía acerca de si la clase social era la clave hermenéutica que descifraría todas las formas de dominación. La EP abrió el espectro de posibilidades, incluyendo a todos los 
desposeídos, con especial énfasis en la población adulta campesina y los sectores marginados de las periferias urbanas. Hoy, sigue siendo un debate importante en el marco de las Ilamadas Pedagogías Críticas (PC) (McLaren, 1997 y Castells et al., 1997) en Colombia (Mejía, 1989) y en América latina (Mejía, 1988); para muchos, la condición de clase es simplemente una más de las razones por las que se discrimina en la sociedad capitalista. Este asunto lo destacamos porque nos interesa ver cómo la tesis marxista de la lucha de clases se desvirtuó, más allá del afán por definir teóricamente cuál fuere la postura correcta.

Lo cierto es que la educación popular se encuentra hoy en día asociada con proyectos pedagógicos que buscan defender los intereses de los grupos poblacionales mencionados arriba, dentro y fuera de la escuela. Aunque nació con una postura radical en contra de ella, pues se consideraba un aparato ideológico del Estado, o como la agencia de un sistema autoritario cuyo modelo pedagógico era bancario (Freire, 1970), en los años 1980 comenzó a plantearse la posibilidad de reivindicar lo popular al interior de sus muros. En Colombia, esto fue parte de un debate también intenso que se dio en el marco del llamado Movimiento Pedagógico (Suárez, 2002 y Peñuela y Rodriguez, 2009). La dificultad que ha tenido la EP para enmarcar la población objeto (trabajadores, campesinos, jóvenes, víctimas de la violencia) y sus ámbitos de intervención (educación formal, o no formal) es de alguna manera expresión de los cambios que está sufriendo la sociedad. Ahora bien, estos cambios están siendo abordados desde muy diversas perspectivas teóricas y por tanto no son descritos ni explicados de la misma manera.

Lo que a continuación pretendemos hacer no es aportar elementos para definir lo que es o no educación popular, o para explicar lo que le ha pasado en su devenir; tampoco vamos a terciar en el debate sobre su carácter de clase o su perspectiva cultural; lo que intentamos es más bien movilizar sus enunciados, más allá de cualquier marco teórico, de manera que pueda desnaturalizarse; será vista como un fenómeno histórico producido en relación con otros acontecimientos que la interceptaron y que ella a su vez atravesó; por tanto, no será una historia de la educación popular, sino aportes para verla en la historia, en un entramado de prácticas de gobierno (Foucault, 2004) donde se definen los discursos pedagógicos contemporáneos. Si se le mira como un acontecimiento que hace parte de un modo de ser de la sociedad, cuyos bordes están definidos por los tipos de veridicción que tienen las prácticas de gobierno contemporáneas, se podrán encontrar nuevas aristas a las prácticas pedagógicas contemporáneas ${ }^{1}$.

1 Como ya se señaló, este artículo toma elementos de la investigación sobre paradigmas de la pedagogía contemporánea en Colombia que se llevó a cabo con el grupo de Historia de la Práctica Pedagógica y otros grupos. Está inscrito en la búsqueda de más largo aliento de nuestras 
No se trata de analizar lo que pasó o de interpretarlo en busca del sentido que habría tenido una u otra práctica; no se trata de encontrar aquellas valoraciones que se acercaban más o menos a su original o auténtica intención; no se trata de mirar lo que sucedió a la luz de un deber ser, o de una preconcepción de lo que deseamos; se quiere ver los enunciados y sus efectos prácticos, aquello que producen, despojándolos de ideologías y de intencionalidades, con sus matices, sus fisuras, sus oposiciones internas, pero sobre todo en sus continuidades, en sus parentescos, sin pretender generalizar o abstraer de allí una esencia o una síntesis que las defina.

Desde esta perspectiva, plantearemos que la eduación popular se configuró en medio de un entramado de prácticas llamadas educación para el desarrollo, en el que se develan conceptos híbridos que constituyen fragmentos de uno o más discursos que los atravesaron por más de tres décadas. Veremos cómo se ha fortalecido el discurso sobre nuevas subjetividades emergentes, poniendo su acento en la alteridad, la diversidad, la subalternidad, la diferencia, la innovación, el cambio y la transformación. Lo que dejaremos planteado es que allí el capitalismo se va renovando, al tiempo que se ve amenazado.

La tesis principal es que las prácticas pedagógicas de hoy están centrándose en la subjetividad del individuo y que tanto la escuela como la educación no formal están promoviendo la emancipación de todo referente que limite la creatividad y la innovación. Este acontecimiento es un proceso de larga duración que no podríamos fechar con exactitud, pues podría incluso estar ubicado en los comienzos de la modernidad misma, o quizas antes; lo que acá vamos a mostrar es cómo durante los últimos sesenta años se ha intensificado y se ha generalizado una manera particular de entender la tarea educativa en la que el individuo es el sujeto de su propia educación ${ }^{2} ;$ y allí las prácticas referidas a la educación popular y la educación para el desarroIlo, así como las que más recientemente promueve el capitalismo cognitivo, han jugado y siguen jugando un papel importante.

tradiciones pedagógicas. Los aportes que se recogen en este artículo no dan cuenta de toda la investigación, pero sí pretenden abrir preguntas nuevas que permitirán avanzar, con otra investigación, en torno a los interrogantes por lo que pasa hoy en día con la educación, la escuela, los maestros, la pedagogía, la enseñanza y el aprendizaje.

2 Esta tesis se ha ido madurando en conversaciones con Carlos Ernesto Noguera, Dora Marín, Cristina León y Gustavo Parra, miembros del grupo de investigación, con quienes estamos profundizando esta mirada. En todo caso, lo que acá se plantea no compromete sus propias tesis. 


\section{Marco de referencia}

\section{La gubernamentalidad liberal}

Según los planteamientos que hiciera Michel Foucault (2004) a propósito de lo que Ilamó la gubernamentalidad liberal, se trataría de una nueva manera de administrar la vida de las personas diferente a lo que había caracterizado a la sociedad disciplinaria. Esta última se habría instalado en la sociedad desde finales del siglo XVIII con prácticas de gobierno centradas en el modelamiento del cuerpo y el alma, en función de los criterios que la modernidad exigía, como la productividad industrial y la vida eficiente en general. Era imperativo entonces adoptar un modo de vida que fuera funcional al cambio y a la vida rápida de las nuevas urbes que se transformaban permanentemente. La educación escolarizada fue una de las exigencias que le dio forma al Estado y a esa sociedad disciplinaria, en cuanto garante responsable de incorporar a la población a estos nuevos hábitos de vida. Desde la pedagogía lancasteriana hasta la pestalozziana, pasando por el panóptico y las instituciones que moldearían alma y cuerpo (hospital, cárcel, ejército, iglesia, escuela), se expandieron ampliamente, constituyendo lo que se ha conocido como el Estado Docente (Álvarez, 2003). En palabras de Foucault (2004), diríamos que el Estado se gubernamentalizó, pues pasó de ser un asunto de las monarquías, cuyo propósito era reinar (administrar un territorio y garantizar su soberanía), a ser un asunto de las repúblicas, cuyo fin era gobernar a la población. Lo anterior supuso convertir en ciudadanos participativos y productivos al servicio de la sociedad a los que antes eran vasallos al servicio del rey.

Pero este tipo de gubernamentalidad comenzó a cambiar desde finales del siglo XIX (lo cual no quiere decir que haya desaparecido), cuando se perfilaban los discursos nacionalistas y el gobierno dejó de ser un modo de intervenir el alma y el cuerpo. El énfasis se puso en crear las condiciones exteriores, ambientales y del entorno propicias para que el individuo reconociera allí lo que le era propio, lo que le permitía identificarse con una nacionalidad particular que lo diferenciaba del ser abstracto-universal que había supuesto la idea de civilización. Una nacionalidad suponía una identidad, y allí el individuo sería activo en esa búsqueda; sería él, como ciudadano de una democracia, quien debería encontrarla, por sus propios medios, pero en un entorno adecuado para ello. La pedagogía entonces se transformó y emergió la escuela nueva, fundamentada en los planteamientos de la psicología experimental; con ella ya no se hablaría de las facultades del alma que habría que modelar, sino de la conducta y el aprendizaje que se debía propiciar: En esta nueva modalidad pedagógica, el protagonista del proceso educativo ya no sería el maestro, el adulto o las disciplinas, sino el niño, 
el sujeto que aprende, el entorno (donde estaría oculto el conocimiento que el niño habría de descubrir).

Gubernamentalidad liberal será pues:

La idea de un gobierno de los hombres que piense ante todo y fundamentalmente en la naturaleza de las cosas y ya no en la mala índole de los seres humanos, la idea de una administración de las cosas que tome en cuenta en primer lugar la libertad de los hombres, lo que estos quieren hacer, lo que están interesados en hacer, lo que piensan hacer (...) un poder que se piense como regulación solo capaz de producirse a través de la libertad de cada uno y con el apoyo de ella. No se trata de una ideología; no es verdadera, fundamental, ni primordialmente una ideología. Es en primer lugar y ante todo una tecnología de poder (Foucault, 2004, p. 71).

A continuación, siguiendo los rastros de la educación popular y sus relaciones con otros acontecimientos que harían parte de este modo de gobernarnos contemporáneo, veremos cómo se generalizó en el caso colombiano para los años 1960 y 1970 y luego los cambios que se produjeron en los años 1980 y 1990.

\section{Las superficies de emergencia}

En primer lugar, veremos aquel conjunto de acontecimientos históricos que marcaron la sociedad en la segunda posguerra. Tales hechos harán resonancia con tres tipos de discursos que se generalizaron también en esa época: los de la institucionalidad estatal, con todos sus proyectos de reforma estructural de la educación, los movimientos de izquierda, agenciando proyectos de autogestión, más allá del aparato escolar oficial, y la Iglesia cristiana, promoviendo también un cambio radical de las estructuras e impulsando proyectos comunitarios al margen de la sociedad de consumo. Todo esto se constituyó en superficies de emergencia de un individuo sujeto de su propio aprendizaje, característico de las modalidades pedagógicas con las que se está poniendo hoy en cuestión la escuela y la educación formal.

\section{La irrupción de un mundo nuevo}

Una gran cantidad de acontecimientos impactaron a los jóvenes durante las décadas del sesenta y el setenta y produjeron una mirada mítica del sentimiento de libertad, que llegó a constituirse 
en un referente para justificar diversos tipos de prácticas más o menos rebeldes, más o menos estéticas, más o menos políticas.

En nuestro país, comenzando la década del sesenta, se sentían los ecos del dolor que había producido la Segunda Guerra Mundial y las heridas frescas que había dejado nuestra violencia bipartidista; al mismo tiempo, se denunciaban los horrores de la guerra de Vietnam (1955-1975) y se hacían anuncios espeluznantes sobre la carrera armamentista de las superpotencias: todo esto se juntaba con otros hechos que dejarían una huella imborrable en por lo menos tres generaciones: los asesinatos de John y Robert Kennedy (19631968) y de Martin Luther King (abril de 1968); la construcción del Muro de Berlín (1961); la caída de Nikita Krushev, y con ella el descubrimiento del Gulag (1964); la Primavera de Praga (1968); el Concilio Vaticano II (1962-1965); la guerra de liberación en Argelia (1954-1962), Mozambique (1964-1974) y Angola (19611975); la Revolución de los Claveles en Portugal (1974); y en América Latina, los cambios revolucionarios en Cuba (1959), el triunfo de Eduardo Frei en Chile (1964) y de Allende (1970) y su posterior asesinato (1973), la muerte del Ché (1967), la matanza de estudiantes mexicanos en Tlatelolco (1968); en Colombia, la muerte del sacerdote Camilo Torres (1968), el robo de las elecciones de 1970, las movilizaciones indígenas en el suroccidente colombiano para recuperar sus territorios ancestrales (creación del Consejo Regional Indígena del Cauca, CRIC, en 1971), la secuencia de paros y huelgas obreras y del magisterio (la Marcha del Hambre del magisterio en 1966 y el paro cívico nacional de 1977). Todos estos episodios, sumados a los cambios muy visibles en la composición demográfica del país y el proceso de urbanización acelerado, marcaron la época y se cruzaron con nuevas búsquedas culturales y sociales que iban desde la experimentación en las artes (música rock y alternativa, nadaismo poético, boom literario latinoamericano) hasta la creación de los grupos insurgentes, pasando por la creación de nuevos hábitos y la proliferación de modas en el vestir e incluso en los sistemas de pensamiento filosófico e ideológico-político. Esto devino en nuevas formas de entender la ciudadanía y, por tanto, en nuevas subjetividades.

Tales hechos podrían analizarse en su singularidad, en la forma azarosa en que se produjeron, o quizás en medio de unas condiciones históricas que las explican. Lo cierto es que fueron años muy convulsionados, de profundos cambios, de agitación, y casi podemos decir de euforia revolucionaria. Independientemente de la perspectiva filosófica o ideológica con la que se les mire, hay una gran coincidencia en reconocer que acá se produjo un quiebre histórico importante.

Por ahora, solo los registramos como eventos que van a incidir en un modo de ser y de pensar que nos interesa caracterizar a propósito de 
la educación que hoy practicamos, cuyo énfasis está puesto en la necesidad de educarnos atendiendo a nuestras propios intereses, siguiendo la racionalidad liberal que mencionamos arriba. Estos hechos, mirados en su conjunto, harían parte de un proceso de inflexión que terminó por acentuar la lógica del gobierno liberal, pero esta vez radicalizando la idea de libertad. Mientras en la primera mitad del siglo XX el entorno debía acondicionarse para permitirle al sujeto encontrar su identidad, durante los años 1960 y 1970, el entorno debía permitirle expresarse según sus deseos más íntimos. Si hubiera que intervenir el espacio (como lo había propuesto la escuela activa), sería para multiplicar las posibilidades que el sujeto tendría de escoger según sus singulares deseos.

El rechazo al orden establecido, que Foucault llamó la fobia al Estado (2007, p. 96), como reacción a los efectos catastróficos del pasado nacionalista, tuvo una variedad de manifestaciones expresadas en los hechos mencionados y formalizadas en un conjunto de movimientos sociales que caracterizaron nuevas subjetividades: el movimiento hippie, el pacifista, el feminista, el antiescuela, contra las prisiones, la antipsiquiatría, el anarquismo, el existencialismo, el ecologismo, el de la autonomía indígena, el de los afrodescendientes, entre otros. En América Latina, se produjo una crisis de la gubernamentalidad liberal que polarizó la lucha política y social en dos tendencias, ambas críticas del Estado liberal: por un lado, las dictaduras (en Colombia el régimen bipartidista) y, por otro, la revolución comunista, campesina, de las clases medias y estudiantiles.

Para nosotros, la educación popular hizo parte de este fenómeno. Lo que vamos a explorar es una lectura de sus prácticas, pero buscando el régimen de veridicción (Foucault 2005, pp. 238-239) en el que se constituyeron, es decir, el sistema de verdades que pugnaron por legitimarse durante las décadas de 1960 a 1980 desde esquinas distintas de la dinámica social; dicho régimen, o dicho sistema, será una superficie de emergencia de las nuevas subjetividades. Luego veremos los efectos de estos años convulsionados, que llamaremos posrevolucionarios (1990 y 2000), traducidos en una nueva discursividad que también tuvo dos expresiones coincidentes en la práctica: los derechos humanos y la perspectiva culturalista del cambio, de un lado, y el posfordismo que propugna por un nuevo modo de producción capitalista ${ }^{3}$. Es-

3 Frente a este asunto, hay actualmente una interesante y disímil lectura. ¿Lo que emerge es una nueva forma del capitalismo? O ¿es una nueva sociedad? Las categorías con la que se nombra son diferentes: se habla de capitalismo cognitivo (Blondeau et 
tos nuevos discursos harán de la educación popular una práctica pedagógica abierta a nuevas exigencias donde tiene que disputar los viejos sueños de autarquía y emancipación (Álvarez, 2003) con la necesidad de formar ciudadanos innovadores, flexibles y autónomos para transar bienes materiales e inmateriales en un mercado libre.

\section{Los discursos oficiales}

Los años sesenta fueron de reformas políticas importantes en el Estado colombiano. El Frente Nacional (1958) supuso una serie de ajustes estructurales al sistema. Entre muchos programas que se crearon en el plano social y económico, destacamos el Ilamado: Plan Estratégico Alianza para el Progreso ${ }^{4}$, desde donde se canalizaron significativos préstamos que buscaban sacar del subdesarrollo (el nuevo nombre de la pobreza) a los países de la región, con programas que ayudarían a disminuir el analfabetismo, impactar el campo a través de reformas agrarias y el ingreso de nueva tecnología en la educación ${ }^{5}$ (televisión educativa e

al., 2004), imperio o multitud (Hardt y Negri, 2002 y 2004), sociedad líquida (Bauman, 2007), sociedad informacional (Castells, 1997b), entre otras perspectivas.

4 En Punta del Este (1961), se firma la Alianza para el Progreso, donde se estableció la ayuda técnica a los países latinoamericanos. Entre otros asuntos, se propusó erradicar el analfabetismo, universalizar la educación primaria y modernizar la enseñanza media para ofrecer formación vocacional y técnica profesional.

5 Estos préstamos fueron hechos por el BID (fundado en 1958). En 1963, fue creada en nuestro país la Oapec (Oficina Administrativa instrucción programada). Allí nació una clara relación entre desarrollo, educación y comunicación, desde donde se promovieron cientos de proyectos orientados a sacar de la pobreza a la población rural para evitar que llegara a marginarse en las periferias urbanas ${ }^{6}$.

El Estado se recompuso en función de las políticas desarrollistas que hablaban de integración, relacionadas con las teorías de la marginalidad que buscaban incorporar a la vida social e institucional a los grupos poblacionales que se consideraban menos favorecidos: los campesinos, los adultos analfabetas de las zonas rurales y de las periferias urbanas. La reforma agraria, la reforma constitucional y la reforma institucional del Estado que realizó el gobierno de Carlos Lleras Restrepo entre 1966 y 1970 son una evidencia para el caso de Colombia.

Se le dio así un extraordinario impulso a la educación de adultos desde la perspectiva del desarrollo de la comunidad. Proliferaron programas y campañas educativas que

para Programas Educativos Conjuntos) para modernizar la escuela primaria. A partir de este momento, se comenzaron a dar cambios en la estructura de la educación, entraron los medios a la escuela con la TV educativa, la radio (ya existía la radio Sutatenza y los programas de acción popular Acpo, financiados por el BM desde 1948), donde se buscaba llegar de forma masiva a la población campesina.

6 Se llevaron a cabo convenios con universidades norteamericanas para preparar en posgrados a profesionales que posteriormente pudieran incidir en la educación de nuestros países. Además, se crearon programas que junto al Sena (Servicio Nacional de Aprendizaje), que ya existia, buscaban adaptar el sistema educativo a los planes de desarrollo económico. 
se regularon a través de diferentes mecanismos. Con el apoyo de Unicef y Unesco, se formuló una definición de la educación básica como la primera fase de una educación que dura toda la vida, la cual implicaba la adquisición de conocimiento, al igual que el desarrollo de actitudes y valores que capacitaran "(...) al individuo no solo para adaptarse a un molde social existente, sino también para vincularse con facilidad a situaciones socioeconómicas cambiantes y aportar su propia contribución a la reforma y al mejoramiento de la vida" (Unesco, 1973, p. 3).

Se estaba consolidando un modo de ser del pensamiento relacionado con la individualización de las estrategias del poder, según el cual el Estado actuaría menos como responsable de la seguridad del ciudadano y más como promotor de la acción del individuo, en cuanto responsable de su propio bienestar. Las teorías del capital humano emergían como una modalidad que afectaría desde ese momento, no solamente las políticas oficiales en educación, sino las políticas económicas y luego el modo de producción.

La consolidación de la teoría del capital humano estaba relacionada con los trabajos de economistas como Robert Solow ${ }^{7}$ (1957), quien centró su atención en el análisis de la productividad y, en especial, en la educación como dinamizadora del crecimiento económico a partir del efecto positivo que ella generaba en el crecimiento del factor residual, o cambio tecnológico, como lo denominó.

Como se ve, el discurso oficial estaba promoviendo una subjetividad capaz no solo de vivir en una sociedad cambiante, sino de promover reformas y convertir al individuo en sujeto de su propia superación. Las reformas que se introdujeron en las políticas educativas transformaron la institucionalidad tradicional: se crearon:

- Los Institutos de Educación Media (INEM).

- Las Concentraciones de Desarrollo Rural (CDR).

- Los Institutos Técnicos Agrícolas (ITAS).

- Cientos de colegios de secundaria.

- El programa Escuela Unitaria, para las escuelas rurales.

7 Robert Solow, economista profesor del Massachussets Institute of Technology (MIT) que obtuvo el Premio Nobel de Economía en 1987, propuso un modelo para determinar el crecimiento económico a partir de una función de producción en la que el cambio tecnológico o factor residual es el que más influye en dicho crecimiento. 
- Las licenciaturas que formaban profesores de secundaria con énfasis en su formación disciplinar.

Se transformaron los contenidos de enseñanza:

- El pénsum escolar se organizó en torno al currículo (entendido como instrucción programada).

- Publicación de las Guías Alemanas (diseño instruccional).

- Modificación del perfil del maestro en las escuelas normales.

- Capacitación masiva de los maestros en ejercicio para implementar el uso de las tecnologías educativas.

Con todo esto, se trataba de producir una nueva experiencia en el proceso de enseñanza-aprendizaje (una pareja de conceptos privilegiada en la época), donde se suponía que el estudiante podía aprender por sí mismo, y que el maestro era tan solo un acompañante y un facilitador de su proceso de autoformación.

\section{Los discursos alternativos}

De manera paralela a las dinámicas implementadas por el Estado emergieron propuestas que hablaban a nombre de los sectores populares, denunciaban la opresión económica, promovían la crítica al establecimiento y acompañaban los movimientos de protesta generalizados en esa época. En ese marco, fueron emergiendo ciertas prácticas denominadas de educación popular, o pedagogía de la liberación, que marcarían en adelante una nueva manera de entender lo educativo (Jara, 2006, p. 12).

Una tendencia del pensamiento de izquierda promovía las ideas socialistas con rostro humanista que acompañaron durante el periodo las prácticas de la educación popular. Su apuesta fue formar una conciencia crítica; esto bajo el supuesto de que la conciencia de cualquier persona estaba en sí misma alienada por los efectos que producía sobre ella la ideología dominante. Para salir del estado de alienación, era necesario vivir una experiencia liberadora que lo constituiría en un sujeto crítico. La perspectiva de estos discursos fue la búsqueda de un hombre nuevo para una nueva sociedad; todo ello alimentado por los debates provenientes de las teorías psicológicas, antropológicas y cristianas (Giraldi, 1975), según las cuales se debían promover los valores de la solidaridad, el sacrificio y la entrega por los demás como modelo a seguir para lograr la humanización de la sociedad, debilitada por el materialismo capitalista y la sociedad de consumo.

El movimiento estudiantil y obrero de mayo del 68 se leyó como parte de un sueño revolucionario. Esto produjo una polarización en torno a lo que se podía o no hacer en el plano de la cultura y de la acción social, dada la generalización de la racionalidad instrumental que denunciaban como una forma de 
dominación. Estas aspiraciones libertarias estaban en sintonía con lo que pasaba en Latinoamérica, donde la polarización había llegado al punto de legitimar la insurrección armada, expresada en los diferentes frentes de liberación nacional. Se abrió una fisura social en la que la revolución se hizo posible, entendida como una pulsión subversiva que dio inicio a una época de guerras civiles más o menos generalizadas en casi todo el continente. La idea de revolución dio lugar a la aparición de movimientos políticos de izquierda en la que jugó un papel importante la clase media emergente. Este nuevo sector social fue sensible a esta causa radical por estar impregnada de un discurso humanista.

El nuevo paradigma enfatiza al hombre como sujeto de cambios, pero solidario con su grupo social. Desde el punto de vista más práctico, se contrapone en el sentido de que tiende a poner la participación al centro de la relación pedagógica (metodología participativa) y en el centro de la organización e investigación educacional (administración e investigación participativa) (Maestro, 1986).

La investigación participante y la investigación-acción vincularon a las personas que realizaban la acción al proceso de investigación. Se transformaba así la acción en un proceso educativo y la investigación en un compromiso social. Para lograrlo, había que buscar un nuevo lugar para el maestro, diferente al que ocupaba en relación con los estudiantes, la comunidad o la escuela en general:

(...) Convertir a los maestros rurales en educadores que trabajen en estrecho contacto con la comunidad y que no solo estén en condiciones de realizar directamente actividades educativas, sino también de promover y cooperar con la comunidad para que las asuma por sí misma. Esto implica imaginar una capacidad adicional para socializar su saber pedagógico en la comunidad y rescatar el saber pedagógico existente en ella. En otras palabras, aplicamos el término educador polivalente a un conjunto de operadores en condiciones de adecuar su rol educativo a una pluralidad de situaciones donde la participación de los sujetos del aprendizaje pasa a jugar un papel fundamental (Vera, 1985).

Muchas de las campañas, programas y proyectos educativos en los que militaban los educadores populares hicieron parte de 
un entramado de discursos relacionados con modalidades educativas que tenían finalidades distintas, pero con acciones similares. Así, la educación para adultos, la educación polivalente y la educación permanente provenían de la Alianza para el Progreso, pero también hacían parte de los proyectos alternativos. Unos y otros educadores se confundían en función de estrategias como la alfabetización, la sistematización, la participación y la comunicación de y con los sectores populares. El hilo conductor, como vemos, fue la idea de ganar autonomía en las comunidades y los individuos para que se hicieran dueños de sus propios procesos educativos y, en últimas, de sus propias vidas.

\section{El discurso religioso}

Sintonizados también con esta discursividad reformadora e impregnada del optimismo y el afán por pensar otro tipo de relaciones sociales y nuevas subjetividades, desde el Vaticano se produjo la llamada nueva doctrina social de la Iglesia ${ }^{8}$. El giro más importante que se dio estuvo relacionado con su posición frente a los procesos de secularización ${ }^{9}$,

8 En palabras del Papa Juan XXIII, quien convocó al Concilio Vaticano II en 1959, se trataba de la necesidad de dejar entrar aire fresco en los ambientes cerrados de la Iglesia; su primera sesión se realizó en 1962, pero un año después el Papa murió; las demás sesiones se llevaron a cabo hasta 1965 y fueron precedidas por el Papa Pablo VI.

9 Para este momento, el cristianismo reconoce la realidad profana, pero la primacía de lo espiritual se mantiene bajo un nuevo contexto. Hay una buena nueva liberadora que se abre a las dando paso al humanismo liberal, que caracterizó la nueva doctrina.

El cristianismo que propuso el Papa Juan XXIII estaba en sintonía con los postulados de Jacques Maritain (París, 1882-Toulouse, 1973), uno de los teólogos más representativos de la corriente renovadora. Este filósofo francés fue destacado defensor del neotomismo, a partir del cual se propuso edificar una metafísica cristiana que él denominó filosofía de la inteligencia y del existir. Su impacto en Latinoamérica se evidenció en la pedagogía de la liberación, diseñada por Paulo Freire, en la que se destacan componentes del discurso de Maritain que vale la pena mencionar:

- Se aparta de lo que llamaron el humanismo burgués, haciendo una clara alusión, desde la concepción marxista de la lucha de clases, a la oposición de intereses que tenía con la clase trabajadora.

- Reconoce las exigencias integrales de las personas.

- Está dirigido a llevar a cabo, en la sociedad temporal, la atención evangélica a lo humano; esto es, ocuparse de

exigencias de la democracia y reconoce la libertad de conciencia. Esta ruptura se produjo en el Concilio Vaticano II (Roma, San Pedro, 28 de octubre de 1965), cuando la Iglesia comenzó a ver la necesidad de abrir sus puertas a otras opciones que se percibían antes como una amenaza; finalmente, aceptaron relacionarse con otras religiones no cristinas para asegurar a estos hombres la entrada al reino de los cielos. 
sus problemas sociales generados por la pobreza: educación, salud, vivienda, trabajo.

- Apunta a la creación de una comunidad fraterna, solidaria, comprometida con los problemas de los otros.

Estas premisas estuvieron presentes en las experiencias brasileñas del Movimiento de Educación de Base y los Centros Populares de Cultura de los años sesenta (Gadotti, 2001), donde Paulo Freire formuló una filosofía educativa que planteaba una renovadora forma de establecer las relaciones entre ser humano, sociedad, cultura y educación. Allí se planteó el concepto de concientización como la base de un proyecto de educación liberadora, en contra de una educación bancaria y domesticadora. Esto suponía un compromiso político inspirado en una fe fortalecida desde la práctica laica de la vida en comunidad. Aunque la prédica de la liberación cristiana se definía como un cambio espiritual, independiente de toda transformación política, esta no podía ser real sin un cambio en las estructuras sociales, lo cual implicaba una lucha política. La confrontación con el enemigo en la lucha política e incluso en la lucha armada llegó a ser un tema de las jerarquías eclesiásticas que encontró uno de sus momentos más radicales en la Conferencia Episcopal Latinoamericana realizada en Medellín en 1968.

Las consignas de la Iglesia hablaban de una inserción en las comunidades, procurando que estas fueran las protagonistas del cambio. El educador popular, desde esta perspectiva, debía hacerse pobre entre los pobres, para desde allí acompañar la lucha de las comunidades buscando satisfacer las Ilamadas necesidades básicas (alimentación, vivienda, democracia, educación liberadora, entre otras). Así, se dio forma a las llamadas Comunidades Eclesiales de Base (CEB), una experiencia que se generalizó en casi todos los países del continente, especialmente en Brasil y Centro América; en ellas se buscaba ganar autonomía frente al Estado y frente a la burguesía, de manera que, con base en el trabajo solidario, se anticipara un modo socialista de producción, a la manera del cristianismo primitivo. Una vez más, se buscaba que las personas y los grupos organizados en comunidad autogestionaran su propia vida en todos los ámbitos, incluyendo, por supuesto, la educación. 


\section{Los efectos posrevolucionarios}

\section{Los derechos humanos y la perspectiva culturalista}

Desde los años 1990, proliferaron nuevas consignas en torno a lo que sería la causa de una sociedad justa y libre. Los derechos humanos fueron una bandera que tendría muy poca discusión en un mundo que comenzaba a redefinirse más allá de la Guerra Fría. Los movimientos alternativos verán sus prácticas interceptadas por nuevos enunciados. Los encontramos descentrados de la lucha de clases, recorriendo otro tipo de relaciones como las de género, las generacionales o las étnicas, pasando por los Ilamados derechos de tercera generación (culturales, económicos y sociales). La caída del Muro de Berlín, la descomposición de la guerra de guerrillas por efectos del paramilitarismo y el narcotráfico, la desmovilización de varios de esos grupos insurgentes, la llamada década perdida del desarrollo y otro tipo de fenómenos propios de los años ochenta desdibujaron el horizonte revolucionario y afectaron el lenguaje y las prácticas de la educación en todos los ámbitos; aunque no se transformaron muchos de sus enunciados, sí aparecieron otros, se afinaron algunos y se intensificaron la mayoría de los que habían proliferado en las décadas anteriores.

En Europa, y particularmente en el mundo anglosajón, los estudios culturales habían hecho su aparición con especial relevancia después de la Segunda Guerra Mundial (Barker y Beezer, 1994); se trataba de un nuevo campo de estudios disciplinariamente más abierto, dispuesto a entender los acontecimientos de la posguerra, marcado por contextos y prácticas muy disímiles. Nuevas formaciones culturales, políticas supranacionales, reorganización de las fronteras nacionales, nuevas formas de organización de la sociedad civil, nuevas intersecciones con el Estado y nuevas configuraciones de clases sociales, todo esto llevó a hablar de una posdisciplina que permitiría combatir los viejos cánones y leer las innumerables demarcaciones de lo que históricamente se había consagrado como verdad; se rompieron los muros de la academia y los conceptos teórico-filosóficos tradicionales para permitir la entrada de otra forma de hablar que le diera un lugar a categorías como raza, género, etnia y, en torno a ellas, las demandas por el reconocimiento de subjetividades diversas.

También en Latinoamérica durante los años ochenta, y en especial en los noventa, surgieron nuevos enunciados que se referían de otra manera a la educación y a la pedagogía. El concepto de diferencia se convirtió en un imperativo ineludible con el que había que aprender a vivir. Esta premisa permitió la rápida inclusión de la educación popular en los referentes de las Ilamadas pedagogías críticas y los estudios culturales, pues compartían la premisa 
de darle un lugar a la diversidad. Allí encontramos una constante que ya se había expresado, aunque no hegemónicamente, el reconocimiento de que las luchas de hoy son moleculares (Lazzarato, 2006). Esto está relacionado con los Ilamados a darle importancia a lo local, a lo cotidiano, la diferencia y las minorías. En ellas se expresaba la voluntad de un cambio más inmediato que ya no se remitía a las llamadas estructuras, sistema, sociedad, modo de producción o relaciones sociales.

(...) Ese trabajador elabora un conocimiento en su relación con el trabajo, con su barrio y su familia, en la medida que organiza su vida; en su relación con los compañeros de clase y de cultura. Allí va elaborando conocimientos específicos, así como explicaciones globales del mundo. Desde ese saber específico, interpreta lo que pasa fuera del mundo que lo rodea (Araujo, Mejía y Balbín, 1988).

En los años ochenta, entre algunos intelectuales críticos y en el seno mismo de las experiencias de la educación popular, se comenzó a poner en duda su eficacia. Se denunció una supuesta cooptación y se habló de la necesidad de una refundamentación. Aunque la discusión fue amplia, por ahora nos interesa destacar el llamado que se hizo a centrar los esfuerzos en las metodologías propias de la reflexión acción, con un claro énfasis en los aprendizajes colaborativos y constructivistas:

Todas las modalidades de autoaprendizaje que favorecen procesos de autoformación deben ser empleadas en los cursos de maestros, extensionistas y otros educadores del medio rural. Aprender a aprender para poder enseñar a aprender. La metodología de autoformación planteada implica la adquisición de un método de reflexión de la propia práctica, y de un método de trabajo grupal y procura habilitar al maestro en un nuevo rol, sobre la base de ir rescatando y criticando su formación anterior y su experiencia acumulada como maestro en una comunidad rural. Es decir, se entiende el aprendizaje como un proceso de modificación de formas de pensar, sentir y de actuar presentes en el sujeto y que se encuentran guiando sus formas de inserción social (Maestro, 1986).

Así, nos encontramos en los años noventa con la proliferación de un discurso que atravesó la institucionalidad misma, según el 
cual lo que importaba en la educación era una práctica que rompiera las jerarquías, democratizara el saber y las relaciones entre la comunidad educativa. Sus principales enunciados tuvieron que ver con la democratización de la escuela, la identidad de género, el respeto a la diferencia, la tolerancia, la convivencia, la no discriminación racial, la ciudadanía crítica, las relaciones no jerárquicas, el diálogo de saberes, entre otros.

\section{El capitalismo cognitivo}

El concepto de capitalismo cognitivo no tiene aún consenso entre quienes analizan las transformaciones en el modo de producción capitalista que se viene produciendo desde la segunda posguerra (Blondeau, 2004); sin embargo, lo utilizamos acá para cobijar aquella perspectiva que muestra cómo ha cambiado el modo de producción y reproducción del capital, para dejar ver el lugar que se le otorga allí a las dimensiones subjetivas del trabajo, $y$, por tanto, el espacio que se le abrió a la educación para atender la diversidad cultural como una prioridad para el capital. En esta coyuntura, se intensificó también un cambio que ya se había iniciado con las políticas internacionales que orientaban el desarrollo. La economía capitalista estaba sufriendo transformaciones significativas en la forma de generar la plusvalía, pasando del énfasis en la producción de bienes materiales a la producción de bienes inmateriales (Virno, 2003). Cambió así el modo de comprender el conocimiento y lo que se consideraba importante saber.

El documento del Consejo Económico para América latina, Cepal (Unesco, 1992), que orientó de manera sistemática los ajustes de los sistemas educativos de todo el continente durante los años noventa, recoge muy bien este planteamiento cuando dice cómo debe ajustarse el sistema educativo a esa nueva realidad. Desde entonces, se deben intensificar en la educación formal dos estrategias fundamentales: el trabajo en grupo, el trabajo colaborativo, que supone ponerse en el lugar del otro, y la autonomía para tomar decisiones en el proceso productivo, la autogestión, y esto supone un componente ético muy fuerte:

$$
\begin{aligned}
& \text { (...) Una economía en } \\
& \text { la que el conocimiento } \\
& \text { ha llegado a ser el prin- } \\
& \text { cipal recurso productor } \\
& \text { de riqueza (...) se debe } \\
& \text { fomentar la capacidad } \\
& \text { para trabajar en grupo } \\
& \text { y capacidad para dirigir } \\
& \text { su propio trabajo (...) El } \\
& \text { tipo de educación que } \\
& \text { se necesita en el futuro } \\
& \text { no solo deberá tener una } \\
& \text { función pragmática, sino } \\
& \text { que deberá centrarse en } \\
& \text { la transmisión de res- } \\
& \text { ponsabilidad social, que } \\
& \text { demanda ética, valores y } \\
& \text { moralidad (p. 105). }
\end{aligned}
$$

Será esencial desde entonces fomentar la creatividad y la iniciativa 
individual a partir de la democratización del proceso, reconociendo y estimulando la diferencia como parte de la estrategia al estímulo para la invención y creación de novedades a partir de la mixtura y el encuentro de la diferencia:

(...) Si la esencia de la nueva economía es el conocimiento, el ideal democrático de la libertad de expresión pasa a ser una prioridad política descollante. Con el auge revolucionario del nuevo sistema de creación de riqueza no es una fracción de la población trabajadora, sino un número sustancial y creciente, el que tiene su productividad precisamente dependiente de la libertad que se le dé para crear todo, desde diseños de nuevos productos, hasta nuevas lógicas informáticas, metáforas, revelaciones científicas y epistemológicas. Las economías supersimbólicas nacen a partir de culturas constantemente estimuladas por nuevas ideas, con frecuencia discrepantes entre las que cabe incluir las ideas políticas (p. 114).

Haciendo eco de las nuevas maneras de hablar de la diversidad, este discurso va a coincidir con quienes, desde una perspectiva crítica, venían cuestionando la escuela represiva y reproductivista. El siguiente párrafo es contundente y parece tomado de un texto de los más radicales defensores de la educación liberadora; sin embargo, es la política oficial, que encarna el llamado de los empresarios y del nuevo modelo económico que promovía la Cepal:

(...) La escuela de hoy debe lo esencial de sus estructuras y de su organización al siglo XIX. Esto se debe a que surgió como una respuesta a dos demandas de la sociedad industrial: por una parte, a la necesidad de prolongar el tiempo de formación para poder contar con mano de obra calificada y con técnicos capaces de leer un plano, calcular y manipular máquinas complejas, por la otra, al imperativo de generar consenso ideológico en torno a los valores de la élite dominante. De allí que sus contenidos valóricos estuvieran impregnados de un fuerte sentido de nación, de respeto a las instituciones y de fe en el progreso y la técnica y que su metodología se basara en la valorización de la medición, la exactitud y el formalismo, en la rigidez intelectual y el raciocinio lineal y mecánico. En suma, se privilegian claramente 
las cualidades de orden y método en detrimento de las facultades creativas.

(...) La educación se transformará en una función vital, tanto para las empresas como para los individuos. Estará integrada al tiempo del trabajo, será cotidiana y continua, no impuesta desde arriba por las empresas o el Estado, sino percibida como una necesidad por los propios individuos (p. 115).

El giro relacionado con la concepción de la educación como una responsabilidad fundamental del individuo, antes que del Estado, buscaba garantizar la autorregulación, de manera que no existiera ningún estímulo externo o una obligatoriedad para promover aquello que el sujeto libremente podría disfrutar: su autonomía para aprender a lo largo de la vida, en todo momento y en todo lugar. El papel del arte y de las humanidades en este proceso será fundamental, pues en ellas, antes que en la ciencia, hay un componente de respeto, tolerancia y libertad que será necesario incentivar.

(...) La vieja sociedad será reemplazada por una sociedad de la enseñanza (...) esto posibilitará en la fase siguiente la sociedad de la liberación, el pleno despliegue de la investigación y de la capacidad creativa, elementos claves de la competitividad. (...) Los nuevos valores del sistema educacional girarán en torno a la idea de creación, del equilibrio de las relaciones entre los individuos, del respeto al espacio del otro como condición del respeto al espacio propio. (...) Se producirá un renacer de los estudios humanísticos y el arte tenderá a integrarse a lo cotidiano (p. 116).

Veamos varios artículos de prensa que dan testimonio de esta nueva perspectiva.

En el Harvard Business Review, se entrevistó al colombiano Rodrigo Arboleda, quien desde hace más de treinta años trabaja en Estados Unidos y es presidente de una fundación sin ánimo de lucro (Fundación 2B1) que recibe fondos de una multinacional (Sega Corporation) y creó una iniciativa para que:

(...) Millones de niños pobres de países en vías de desarrollo puedan tener un computador portátil para conectarse a Internet. (...) Para Arboleda, la creación de riqueza en este siglo se hará por medio de la propiedad intelectual, a diferencia del siglo pasado, en el que la manufactura mandaba la 
parada. El colombiano señala que lo más importante en este siglo es aprender a aprender, porque ahora, debido a la gran cantidad de cambios, hay que aprender y desaprender constantemente. Por eso, señala que hacen falta más innovadores y menos administradores del statu quo (Rodríguez, 2008).

En otra nota periodística, se preguntaba por los factores claves para el aprendizaje organizacional:

(...) 1. Apoyo al aprendizaje: seguridad psicológica: para aprender, los empleados no pueden temer, deben sentirse cómodos al expresarse. Apreciación de las diferencias: el aprendizaje ocurre cuando las personas toman conciencia de las ideas discordantes. Reconocer el valor de visiones de mundo alternativas aumenta la motivación. Apertura a las ideas nuevas: no solo se trata de corregir errores y resolver problemas. También es crear enfoques novedosos. Tiempo para la reflexión: cuando las personas están demasiado ocupadas o estresadas, su capacidad para pensar de manera analítica y creativa se ve debilitada. 2. Procesos y prácticas: los procesos de aprendizaje incluyen la generación, recopilación, interpretación y diseminación de la información. Para que tenga máximo impacto, el conocimiento debe compartirse de forma sistemática y definida. El conocimiento se puede mover lateral o verticalmente. El ejemplo más conocido de este enfoque es el proceso de evaluación después de la acción (AAR, After Action Review) del Ejército de E. U., que hoy se usa en muchas empresas, y que es una entrega de información sistemática después de cada misión (Garvin, Edmondson y Gino, 2008).

Entre las recomendaciones de los empresarios exitosos para mejorar la rentabilidad de los negocios, en otro artículo del New York Times se planteaba:

1. Promueva el trabajo en equipo: casi todo trabajo requiere un esfuerzo de equipo para que sea efectivo. Las investigaciones demuestran, una y otra vez, que los grupos resuelven los problemas de una manera mejor que los individuos por su propia cuenta. Además, los trabajadores, en su mayoría, se motivan grandemente cuando trabajan en equipo. 2. Escuche e involúcrese: los empleados son 
una rica fuente de información sobre cómo hacer un trabajo y cómo hacerlo mejor. Este principio se ha demostrado una y otra vez con toda clase de empleados. Los gerentes que operan con un estilo participativo cosechan enormes recompensas en eficiencia y calidad de trabajo. Los gerentes participativos dan a los empleados libertad para operar y hacer cambios por su cuenta, basados en sus conocimientos y experiencia. No existe una táctica motivacional más poderosa que darle libertad a la gente competente de hacer su propio trabajo como lo crea conveniente (Sirota, Mischkind y Meltzer, 2008).

Guillermo Santos, quien fuera uno de los dueños del periódico $E$ I Tiempo, en su columna habitual sobre el mundo de la tecnología, escribía sobre esta estrategia así:

(...) Para empoderar a las masas se requiere un cambio de mentalidad en los niveles ejecutivos. Entender que cualquier empleado, sin importar su nivel, puede proponer una idea que no se les había ocurrido a sus directivos. Pues Ilegó el momento de aceptar y acoger la inteligencia colectiva (Santos, 2008).
En todos estos registros se puede evidenciar cómo las características de estos enunciados, que han operado en múltiples escenarios, se interceptan y se complementan, con matices y con énfasis diferentes, con aquellos formulados por los discursos críticos de los años setenta y con los afanes por salir de la pobreza y el atraso, propio de los desarrollistas. Es decir, aquello que fuera propio del movimiento de la Educación Popular hace tres o cuatro décadas: la lucha por la autonomía, la autogestión, la libertad, la solidaridad, la horizontalidad en las relaciones, ahora es un discurso promovido y agenciado por las multinacionales y las grandes corporaciones que representan las marcas que hegemonizan la sociedad de consumo hoy en día.

\section{Conclusión}

Se quiso ver el entramado discursivo en el que se configuró una nueva manera de entender la educación, en dos momentos distintos, cada uno con sus superficies de emergencia: para los años 1960 a 1980, la educación oficial, la educación popular y la teología de la liberación; para los años 1990 a 2000, los estudios culturales y el capitalismo cognitivo. Para poder entender este fenómeno de transposición discursiva, hemos hecho una rápida semblanza de aquellos puntos por donde pasó y las prácticas que las registraron, para finalmente verla emerger a partir de un conjunto de mecanismos y 
procedimientos que la hicieron funcionar. De sus modos de operar en el discurso ha surgido la idea de que hoy es el individuo el responsable de su propia educación. Y este postulado es el acontecimiento que nos interesó reseñar.

Los efectos de este nuevo acontecimiento están por verse. Lo cierto es que están proliferando nuevas modalidades educativas, como las de home school, o el sistema Waldorf, además de las Ilamadas metodologías flexibles por parte del Ministerio de Educación ${ }^{10}$, entre las cuales se encuentran: aceleración del aprendizaje, escuela nueva, posprimaria, telesecundaria, servicio de educación rural (SER), programa de educación continuada (Cafam), servicio de aprendizaje tutorial (SAT), propuestas educativas para jóvenes y adultos (A Crecer).

De otra parte, proliferan las críticas a la escuela, al maestro y a las instituciones formadoras de maestros, coincidiendo en ello diversos sectores: los empresarios, los medios de comunicación, los defensores de los derechos humanos y en particular de los movimientos defensores de los jóvenes, las mujeres, las negritudes, los indígenas, los LGTBI, los desplazados, en fin. Entre las muchas críticas que se siguen haciendo de manera persistente ha hecho carrera la denuncia por el matoneo en la escuela, al punto que se la responsabiliza de los altos índices de suicidio juvenil. Una nota reciente en la gran prensa muestra cómo se valora un tema que se ha puesto de moda:

El Instituto Nacional de Medicina Legal de Colombia evidenció que empezando el año, entre enero y mayo, se presentaron 67 casos de suicidios de niños, niñas y adolescentes. Irene Pachón tiene su propia tesis, y es que la depresión de los niños y jóvenes, producto de la aceleración de sus ritmos biológicos y de aprendizaje; la implementación de un modelo competitivo basado en la calificación y el desarrollo del hemisferio cerebral derecho -el de la lógica matemática y la razón-, y no el del izquierdo que potencia la creatividad, el arte y la sensibilidad, son los principales factores que generan esas determinaciones en los adolecentes (El Espectador, sábado 20 de julio de 2013, p. 48). 
Estos indicadores de violencia escolar son ciertamente alarmantes, pero también lo son los índices de enfermedades nerviosas que registran los maestros y los problemas de deserción escolar que, en vez de disminuir, aumentan. La alternativa que se promueve hoy es la de el estímulo a la creatividad, la sensibilidad y el arte, con lo cuál se está abandonando la vieja idea (desde hace cuatrocientos años) de enseñar en la escuela los códigos que formalizan el acceso a la modernidad.

La actualidad y la intensificación de estas críticas nos han Ilevado a preguntarnos por lo que le está pasando hoy a la educación, y en esa búsqueda nos encontramos con el proceso de deslegitimación de la educación escolarizada. Allí apareció la educación popular, ligada a otros regímenes discursivos, con diversas procedencias, haciendo parte de dichas críticas.

No es fácil predecir lo que va a pasar con la escuela, porque está visto que se actualiza y se reconfigura de muchas maneras dentro y fuera de sus propios muros. No se trata además de hacer de profetas de ningún nuevo anuncio liberador; más bien se trata de mostrar de dónde proviene este presente e identificar el acontecimiento más contemporáneo: la deslegitimación de la educación escolarizada y la emergencia de nuevos modos de gobierno que proliferan a veces sin ser vistos. Pero esta tarea no acaba acá. Necesitamos documentarnos mucho mejor para comprender este presente que tercamente se nos presenta incierto. Tal incertidumbre, quizás, es parte de este modo de ser del presente. Debemos pues iniciar de nuevo nuestras búsquedas, para identificar a fondo esas otras procedencias que, al cruzarse con la educación popular, nos están despojando de las viejas certezas y nos provocan para inventar otras nuevas.

\section{Referencias bibliográficas}

Castells, M. et al. (1997a). Nuevas perspectivas críticas en educación. Barcelona: Paidós Educador.

Castells, M. et al. (1997b). La era de la información. Madrid: Alianza.

Foucault, M. (2004). Seguridad, territorio, población. Buenos Aires: Fondo de Cultura Económica.

Foucault, M. (2005). El poder psiquiátrico. Buenos Aires: Fondo de Cultura Económica.

Foucault, M. (2007). Nacimiento de la biopolítica. Buenos Aires: Fondo de Cultura Económica.

Freire, P. (1970). Educación como práctica de la libertad. Bogotá: Ediciones de Convergencia.

Gaddotti, M. (2001). Paulo Freire, una biobibliografía. México: Siglo XXI Editores.

Garvin, D., Edmondson, A. y Gino, F. (2008). Organizaciones que aprenden. El Espectador, 22 de septiembre.

Giraldi, J. (1975). Educación integradora y educación liberadora. 
Bogotá: Publicaciones SINAE, Servicio de Investigación y Acción Educativa.

Hardt, M. y Negri, A. (2002). Imperio. Buenos Aires: Paidos.

Hardt, M. y Negri, A. (2004). Multitud. Barcelona: Debate.

Jara, O. (2006). Sistematización de experiencias y corrientes innovadoras del pensamiento latinoamericano. Una aproximación histórica. La Piragua. Revista Latinoamericana de Educación y Política, 23, 8-16.

Lazzarato, M. (2006). Políticas del acontecimiento. Buenos Aires: Tinta Limón.

Maestro, G. (1986). Bibliografía anotada sobre educación polivalente. Santiago de Chile: Unesco.

Mejía, M. (1988). Itinerario temático de la educación popular. Santiago de Chile: Consejo de Educación de Adultos de América Latina.

Mejía, M. (1989). Cuestionamientos sobre la educación popular. Bogotá: Documentos Ocasionales, Centro de investigación y educación popular (CINEP).

McLaren, P. (1997). Pedagogías críticas y cultura depredadora. Políticas de oposición en la era posmoderna. Barcelona: Paidós.

Peñuela, D. y Rodríguez, V. (2009). Movimiento Pedagógico: realidades, resistencias y utopías. Bogotá: Universidad Pedagógica Nacional.

Rodríguez, M. (2008). Una organización de aprendizaje. El Espectador, lunes 22 de septiembre.

Santos, G. (2008). Nueva inteligencia. El Tiempo, 28 de abril.

Sirota, D., Mischkind, L. y Meltzer, M. (2008). No siga desmotivando a sus empleados. Bogotá: Harvard Business School Publishing.

Suárez, H. (comp.) (2002). Veinte años del movimiento pedagógico. 1982-2002. Entre mitos y realidades. Bogotá: Magisterio-Tercer Milenio.

Unesco. (1974). Reunión de expertos sobre el Ciclo de Educación Básica. Informe Final. París: Unesco.

Unesco. (1992). Educación y conocimiento: eje de la transformación productiva con equidad. Santiago de Chile: Unesco.

Vera, R. (1985). Programa Regional de Desarrollo Educativo. Bogotá: PREDE/OEA - IICA.

Virno, P. (2003). Gramática de la multitud. Para un análisis de las formas de vida contemporáneas. Buenos Aires: Ediciones Coluhue. 